\title{
The heritability of attained growth in the human face
}

\author{
W. Stuart Hunter, D.D.S., Ph.D., Daniel R. Balbach, D.D.S., M.S., and \\ Donald E. Lamphiear, B.A., M.A. \\ London, Ontario, Canada, and Ann Arbor, Mich.
}

$\mathrm{T}_{\mathrm{h}}$ he purpose of this study was to determine whether the size of several facial dimensions in human adults may be predicted from the size of the same dimensions in the parents.

In the past 30 years some six or seven studies have been reported in which heritability in the human face has been studied across at least two generations, usually in an effort to detect the mode of inheritance in the classic Mendelian fashion. Studies by Curtner, ${ }^{1}$, Iwagaki, ${ }^{-2}$ and Moore and Hughes ${ }^{3}$ have such an orientation, in which a trait is seen to exist or not to exist in a qualitative fashion. Other studies by Stein, Kelly, and Wood ${ }^{4}$ and Wylie ${ }^{5}$ have attempted, on the other hand, to assess quantitative measurements in the face across generations. However, these studies utilized growing children. At best, a growing child is a moving target, as far as heritability studies are concerned, since growth occurs at different times and at different rates for different subjects. Furthermore, it has been shown that the shape of the face alters during growth. ${ }^{6-8}$ The study of facial similarities between parents and their adult offspring (that is, offspring who have stopped growing) was undertaken with the hope that prediction of future completed size of the face would be sufficiently accurate to be useful in the estimation of remaining facial growth potential at or before puberty.

\section{Method}

Standardized lateral cephalograms were collected of families in which both parents and two or more children 21 years of age or older were available for study. Thirty-one such families were recorded. Also included in the sample were

From the University of Micligan Center for Human Growth and Development and the Department of Paediatric Dentistry, University of Western Ontario.

This study was supported by United States Public Health Service Grant HD 02272 and by the Medical Research Council of Canada Grant MA 3547. 


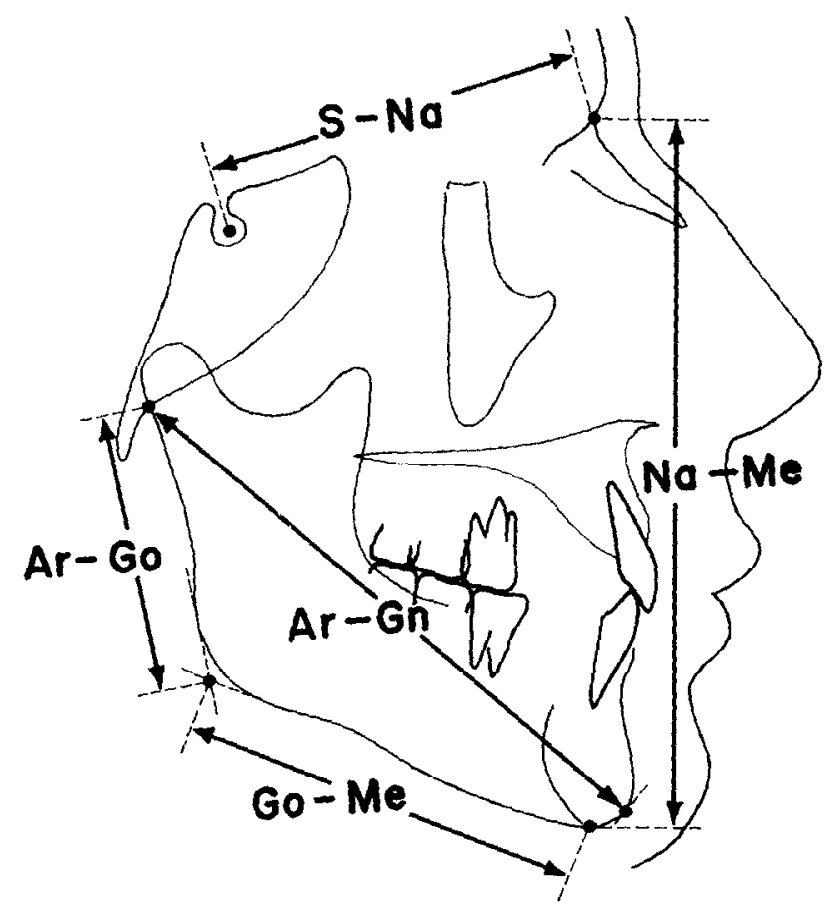

Fig. 1 .

seren families in which one or both children were from 17 to 21 years of age. Not all of the families hat both sons and daughters. There were thirty-one families in which parent-son comparisons could be made and twenty-seven which provided parent-daughter comparisons. In families for which two or more likesexed siblings were available, only the data for the oldest sibling of that sex were used for this report, sinee the use of two or more like-sexed offspring, where they occur, woukd involve using the same parent more than once and thus bias the findings.

The sample was obtuined over a 3-year period in Ann Arbor, Michigan, and consists, with few exceptions, of established middle-class families of European athric origin. No adoptive or step relationships aro known to exist in the sample. With two exceptions, all suhjects could establish ecelusal contact with at least some posterior teeth of their uwn.

The recordings consist of standardizet latoral ephalograms tor cath subjeet with subject-film distance held constant for all subjects. Five tacial dimensions (Fig. 1) were recorded from the tracings of the lateral cephalograms. These dimensions had been found to be highly inherited relatire to other measurements tested in a previously reported twin study by Hunter' in which fourteen depth measurements and twelve height measurements were studied in a sample of seventy-two like-sexed twins. All tracings and measurements were repeated to eliminate gross errors.

Correlation coefficients were computed between measurements within each 
group of parents (fathers, mothers) and offspring (sons, daughters) to determine the relationship between the measurements for individuals and also between parents and offspring to determine the effect of parents' measurements on those of the offspring. While individual correlation coefficients are of interest in themselves, eomplex relationships between groups should not be inferred from a study of the correlation coefficients alone because of the relationships which exist between measurements within individuals. In order to evaluate such interrelationships, multiple regression analysis was performed, with the parents measurements used to predict each measurement of the sons and daughters.

\section{Findings}

Correlation coefficients between fathers' and mothers' measurements were computed for the five variables over the thirty-eight sets of parents. None of the correlations were significantly different from zero. Hence, assortative mating as a causative factor was excluded from further consideration in the interpretation of the data.

Correlation coeffieients between the five variables in the parents and offspring were examined. It was observed that the most significant correlations occur between the corresponding measures in fathers and offspring. This relationship was not as clear between mothers and offspring, for whom the only relationships which were statistically significant were those for face height (Na-Me) for mothers and daughters and mothers and sons.

A summary of the simple correlation coefficients between corresponding measurements in parents and offspring is presented in Table I, in which it may be seen that the strength of the statistical relationship between fathers and sons and fathers and daughters is similar. A comparison of correlations with mothers to correlations with fathers indicates a consistently higher correlation for the relationship between corresponding measurements of fathers and offspring than between corresponding measurements of mothers and offspring. A number of correlations are significantly greater than zero, but in only one ease is the difference between two corresponding correlations statistically significant. The correlation between fathers' and sons' Ar-Gn measurement is greater than the corresponding correlation between mothers and sons at the 5 per cent level of significance.

Table 1. Correlation coefficients between corresponding measurements in offspring and parents

\begin{tabular}{c|c|c|c|c}
\hline Variables & Father-son & Father-daughter & Mother-son & Mother-daughter \\
\hline Ar-Go & $0.573^{* *}$ & $0.492^{* * *}$ & $0.166^{*}$ & 0.039 \\
Go-Me & $0.409^{*}$ & $0.518^{* *}$ & $0.398^{*}$ & 0.282 \\
$\mathrm{Na}-\mathrm{Me}$ & $0.312^{*}$ & $0.448^{*}$ & $0.370^{*}$ & $0.382^{*}$ \\
$\mathrm{~S}-\mathrm{Na}$ & $0.481^{*}$ & $0.459^{*}$ & 0.217 & 0.052 \\
$\mathrm{Ar}-\mathrm{Gn}$ & $0.639^{* *}$ & $0.619^{* *}$ & 0.192 & 0.231 \\
$\mathrm{~N}$ & 31 & 27 & 31 & 27 \\
\hline
\end{tabular}

Statistical significance: ${ }^{*} 5$ per cent, ${ }^{* *} 1$ per cent, ${ }^{* * *} 0.1$ per cent. 
The multiple regression analysis confirmed the pattern already observed with the simple correlation coefficients and provided some additional results. The most significant variable for predicting a measurement in the offspring is the corresponding measurement in one of the parents. For the present data, the fathers' corresponding measurement provides the greatest amount of information in all measurements except the sons' $\mathrm{Na}-\mathrm{Me}$ dimension, for which the mothers' Na-Me measurement is a better predictor. Generally, the fathers' measurements of other variables have greater predictive value than the mothers', but again the regression equation for $\mathrm{Na}-\mathrm{Me}$ is an exception. Finally, regression equations based on the significant variables for both parents give better results than those based on a single parent."

\section{Discussion}

The most noticeable feature in the data of this study is the much stronger relationship between fathers and offspring than between mothers and offspring. The highest correlation between parents and offspring which is compatible with a theory of polygenic inheritance is $0.50 .^{10}$ The father-offspring correlations fit such a theory rather well and support the concept that facial dimensions have a significant heritable component. The mother-offspring correlations do not. Although the differences between father-offspring and mother-offspring correlacions, considered singly, are not generally significant, in the aggregate they are, which suggests that either the sample is quite biased or that the mother-offspring pattern of inheritane is not entirely polygenic. In the absenee of additional data, consideration of both sample bias and nonpolygenic inheritance must await further study.

The only exception to the pattern discussed here is the relationship between mothers and offspring for the face height dimension, which is much the same as that for fathers and offspring. On the other hand, the relationships for the three mandibular measurements very much favor the father-offspring moiety. In the previously mentioned study of twins," the mandibular measurements on the whole showed a lower and less significant level of heritability for male than for female twins. Thus, it might be expected that mother-offspring relationships for the same measurements would be stronger than father-offspring relationships. The reverse was found in the present study, and again the possibility of sample hins makes further interpretation hazardous.

Sinee the subjects in this study are postpubertal, the impact of maturation on heritability camnot be observed direetly. However, it might be noted that, where comparable, the correlations reported here are generally higher and more often significant statistically than those reported in a series of recent studies which analyzed dentofacial relationships between parents and growing offspring. ${ }^{12-1+4}$

A measure of the practical significance of the regression equations is the per cent reduction in errors achieved by using regression equations insteal of sample means for predicting attained growth, presented in Table II. For example, the

\footnotetext{
"Complete results of the regression analysis are available on request from the authors.
} 
Table II. Reduction in errors of prediction by the use of regression equations

\begin{tabular}{|c|c|c|c|}
\hline \multirow[b]{2}{*}{ Dependent rariable } & \multirow[b]{2}{*}{$\begin{array}{c}\text { standard deviation in } \\
\text { sample of offspring }\end{array}$} & \multicolumn{2}{|c|}{ Results of most efficient regression equation } \\
\hline & & $\begin{array}{l}\text { Standard error } \\
\text { of estimate }\end{array}$ & Per cent reduction \\
\hline & & \multicolumn{2}{|c|}{ Sons on both parents } \\
\hline$A r-G_{0}$ & 7.49 & 5.78 & 22.8 \\
\hline Go-Me & 5.60 & 4.88 & 12.9 \\
\hline $\mathrm{Na}-\mathrm{Me}$ & 7.64 & 6.55 & 14.3 \\
\hline $\mathrm{Se}-\mathrm{Na}$ & 3.91 & 3.11 & 20.5 \\
\hline \multirow[t]{2}{*}{$A r-G n$} & 0.93 & 5.42 & 21.8 \\
\hline & & \multicolumn{2}{|c|}{ Daughters on both parents } \\
\hline Ar-Go & 3.97 & 2.54 & 36.0 \\
\hline Go-Me & 2.54 & 2.03 & 20.1 \\
\hline $\mathrm{Na} \cdot \mathrm{Me}$ & 6.53 & 4.97 & 23.9 \\
\hline $\mathrm{Se}-\mathrm{Na}$ & 3.55 & 3.00 & 15.5 \\
\hline Ar-Gn & 3.82 & 2.80 & 26.7 \\
\hline
\end{tabular}

use of the most efficient regression equation, based on variables from both parents, reduces the confidence interval (which is proportional to the standard deviation) 27 per cent for the measurement of the daughters' mandibular length (Ar-Gn). A somewhat less efficient equation, based only on the fathers' measurements, shows a 23 per cent reduction, while the equation based solely on the mothers' measurements shows only a 9 per cent reduction in the standard error of estimate. The range of reduction of the standard deviation when both parents' variables are used (midparent value) is from 12.9 per cent to 36 per cent.

These reductions in variability may be compared with those reported by Johnston. ${ }^{2 \bar{s}}$ In a definitive evaluation of prediction procedures using cephalometric data, he found regression equations which achieved reductions in the standard error of estimate ranging from 30 per cent to 54 per cent when using an individual's facial dimensions at one age to predict the size of a future facial dimension. In another study by Balbach, ${ }^{16}$ using mandibular measurements of boys at 7 years to predict S-Cn at 11 years, a 62 per cent reduction in errors of estimate was found. These are clinically useful reductions in variability. The reduction accomplished by using parents' data alone, at least as explored in this study, is not. Thus, it appears that the information provided by the individual about his future facial dimensions is more useful than information from his parents. It should be noted, however, that Johnston's data did not go beyond age 13 and Balbach's beyond age 11. Thus, they dealt with essential$1 y$ prepubertal growth and avoided the highly variable (with repect to onset, duration, and intensity) pubertal period of facial growth. The data of this study permit the evaluation of quite different parameters- the cross-generation relationship of attained growth. Hence, the reduction in variability accomplished by using parents' data should be partially independent of that accomplished by using the subject himself. Furthermore, this study deals with 
averages, and quite different results might be anticipated when extremes of facial size are followed aeross generations.

\section{Summary and conclusions}

A cephalometric study of thirty-eight families was undertaken to determine the heritability of facial dimensions. Adult oftspring were compared with both parents, thus minimizing variations due to timing and rate of growth. Simple correlation coefficients were calculated, and a multiple regression analysis was performed to determine the statistical relationship between parents and their offspring.

The high values of $r$ found in this study support the conclusion that facial dimensions are largely inherited.

The statistical relationships were strongest between fathers and offspring and were consistently highest between the same measurements in parents and oftspring. The relationships between fathers and offspring were particularly strong for the mandibular dimensions.

The statistical relationships between mothers and offspring were lower than those between fathers and offspring. The only consistently significant relationship for the former was that for facial height between mothers and their offspring. The relationships between mothers and offspring were quite weak for the mandibular dimensions.

The regression equations using parental facial dimensions were of questionable dinieal value when used to prediet the adult dimensions in offspring. Although the standard errors of estimate were redued significantly, they still were large from a clinical standpoint.

Finally, the departure of the mother-offspring relationship in this sample from values anticipated under a theory of polygenic inheritance merits further exploration, as does a consideration of the extremes of facial size across gener. ations.

The authors ase indebtel to the families of Ann Arbor and Takson, Mich., who contrib. uted their time to provide data for this study and to Richard I. Miller and Barbara I. Reid for technical assistanee in preparation of the data. We also wish to thank Drs. R. E. Moyers, W. J. Schull, and S. M. Garn for critical comments and ancouragement at various stages of the study.

\section{REFERENCES}

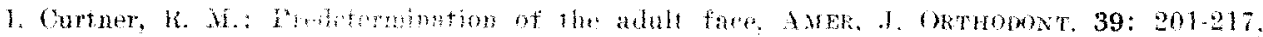
1953.

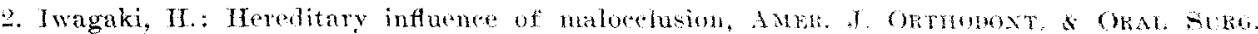
24: $328-336,1938$.

3. Moore, G. R., and Hughes, B. O.: Familial tactors in dentofacial disturbance, Amer. J ORTHonont. \& ORAL StRG, 28: 603-639. 1942.

4. Stein, K. F., Kelly, T. T., and Wood, E.: Infuence of heredity in the etiology of maloe. clusion, AMer. I. ORThodontr. 42: 125-141, 1956.

5. Wylie, W. J.: A quantitative method for the comparison of cranofaciat patterns in different individuals, Amer. J. Anat. 74: $36 \cdot 60,1944$.

6. Brodie, A. G.: Late growth changes in the louman fuce, Angle Orthodont. 23: 146.15\%, 1953. 
7. Lande, M. S.: Growth behaviour of the human bony profile as revealed by serial eephalometric statiktical appraisal of dentofacial growth, Angle Orthodont. 32: 205-213, 1962.

s. Merow, W. W.: A cephalomotrie statistimal apprisal of dentofacial growth, Anghe Orthodont. 32: 205-213, 1962.

9. Hunter, W. S.: A study of the inheritance of craniofacial characteristies, Trans. Europ. Orthodont. Soc., pp. 59-70, 1965.

10. Li, C. C.: Human geneties: Principles and methods, New York, 1961, MeGraw-Hill Book Company, Inc.

11. Johnson, R. S.: Inheritance of the eraniofarial complex; mother-daughter, Master's thesis, University of Michigan, 1968.

12. Masty, J. A.: Inheritance of the craniofacial complex; father-son, Master's thesis, University of Michigan, 1968.

13. Roshel, .T. A.: Tnheritance of the rmofofacial complex; father-daughter, Master's thesis, University of Michigan, 1968.

14. Warren, P.: Inheritance of the craniofacial complex; mother-son, Master's thesis, University of Michigan, 1968 .

15. Johnston, L. E.: A statistical evaluation of cephalometric prediction, Angle Orthodont. 38: 284-304, 1968.

16. Balbach, D. R.: The eephalometric relationship between the morphology of the mandible and its future occlusal position, Angle Orthodont. 39: 29-41, 1969.

Just as we today look back over the period of a generation and pay homage to these teachers, so let us work, plan, and so direct our energies that the young men of today, who within another generation will look back and make a survey of that period through which we are now passing, will find our work well done, and our investigations properly and nobly made. Further, let us see to it that they shall be unable to point a reproachful finger at any of us, and let us hope that they may take time to pay such respect and offer such commendation as our efforts in their behalf may merit. (Fisher, William C.: President's address, Transactions of the first [1926] International Orthodontic Congress, St. Louis, 1927, The C. V. Mosby Company, p. 5.1 